\title{
Characteristics of a Simple Monitoring System for Trichloroethylene Using a Hybrid Quartz Crystal Microbalance
}

\author{
Kazutoshi Noda*, Hidenobu Aizawa and Shigeru Kurosawa \\ National Institute of Advanced Industrial Science and Technology (AIST), \\ AIST West, 16-1 Onogawa, Tsukuba, Ibaraki 305-8569, Japan
}

(Received February 7, 2008; accepted May 8, 2008)

Key words: trichloroethylene, volatile organic compounds, oxidizing agents, quartz crystal microbalance, hybrid, gas sensor

A simple and highly sensitive monitoring system for the detection of trichloroethylene (TCE) using a hybrid quartz crystal microbalance (hybrid QCM) is described. This hybrid QCM system uses lead dioxide and sulfuric acid as oxidizing agents to convert TCE into hydrogen chloride, which in turn reacts directly with a copper electrode on the quartz crystal surface. The results of experiments indicate that the sensitivity increases at higher temperatures. In addition, an increase in the amount of oxidizing agent used does not necessarily lead to a larger frequency shift, although the frequency shift does depends on the TCE concentration. Using a calibration curve, it is possible to obtain the TCE gas concentration. In the case of $100 \mathrm{ppb}$ TCE, a frequency shift of $27 \mathrm{~Hz}$ is obtained using a $12 \mathrm{MHz}$ QCM. This new detection system allows for measurement of very low concentrations of TCE and has a detection limit comparable to the Japanese environmental standard $\left(0.2 \mathrm{mg} / \mathrm{m}^{3}\right)$.

\section{Introduction}

Soil and groundwater environmental pollution problems caused by volatile organic compounds (VOCs) such as trichloroethylene (TCE) have become the focus of a great deal of interest in the past few years. ${ }^{(1,2)}$ Among these VOCs, TCE has attracted attention because low-level, chronic TCE pollution may cause the development of allergies and increase cancer rates in humans.(1) In the past, TCE was used in large quantities for cleaning semiconductor devices at semiconductor factories and is currently used in small quantities in other industries.

The environmental problems associated with TCE occur primarily at facilities that had used TCE before Japanese environmental standards for air and water were revised, ${ }^{(1,2)}$ and in the land after such facilities were removed. These problems are not,

*Corresponding author: e-mail: kazu-noda@aist.go.jp 
however, limited to high-level local pollution surrounding such facilities. The local pollution is spreading and producing low-level, extensive pollution, mainly through air and groundwater.

In the context of these problems, the Soil Contamination Countermeasures Law, which obliges landowners to remediate contaminated soil, was implemented (2) in 2003. The environmental standard value for TCE in groundwater was set to $0.03 \mathrm{mg} / \mathrm{l}^{(2)}$ In addition, TCE was designated as a "hazardous air pollutant" under the Air Pollution Control Law, and the environmental standard value for the yearly average concentration of gaseous TCE was set to $0.2 \mathrm{mg} / \mathrm{m}^{3}$ (about $37 \mathrm{ppb}$ at $25^{\circ} \mathrm{C}$ ). (2) $\mathrm{TCE}$ is on the priority substance list; therefore, immediate measures to reduce its emission are required.(1,2) Ordinary, these low concentration compounds are usually determined by gas chromatography with an electron captures detector (GC-ECD). However, this requires skillful operating technique, and it is not possible to measure TCE in real time. The gas detecting tube method is also widely used since the method is simple and easy, but the sensitivity is not sufficient for our purpose. These concerns have created a strong demand for a simple method that allows for the easy, highly sensitive measurement of TCE. Previously, we developed a highly sensitive method capable of detecting the presence of low concentrations of TCE using a quartz oscillator. ${ }^{(3)}$

To measure concentrations of TCE as low as $0.2 \mathrm{mg} / \mathrm{m}^{3}$, the Japanese environmental standard value for gaseous TCE, we previously developed a method that uses an oxidizing agent that converts TCE into hydrogen chloride, which in turn reacts with the electrode of a crystal oscillator and thereby leads to a decrease in the frequency shift.(4)

The operating principle of a quartz crystal microbalance $(\mathrm{QCM})^{(5)}$ is as follows. As a substance is adsorbed onto the electrode on the surface of the oscillator, a change in the electric resonance frequency due to the piezoelectric properties of the oscillator occurs in proportion to the mass change caused by the adsorption. Using this phenomenon, a trace amount of adsorbent can be quantitatively measured. This basic detection principle was reported by Sauerbrey, and the basic equations for a QCM are presented in his paper. ${ }^{(5)}$ Since then, many applications of the QCM that allow real-time measurements using this basic principle have been reported. ${ }^{(6-10)}$ In the context of this research, we have investigated applications of the QCM to environmental pollutants and have conducted research on simple environmental problems that require quick and easy measurements. ${ }^{(3)}$

We have already developed a simple measurement method for TCE that utilizes a chemical reaction between an oxidizing agent and the copper electrodes of a quartz oscillator. $^{(4)}$

Copper was used as the electrode material in this study on the basis of the results of a previous investigation in which a copper electrode exhibited the largest change in oscillating frequency compared with other metal electrodes (gold, silver, platinum, chromium, nickel, and titanium). ${ }^{(4)}$ Some metals not only physically adsorb HCl but also chemically react with $\mathrm{HCl}$ on their surfaces. However, unlike other metals, copper readily reacts with $\mathrm{HCl}$ to form copper chloride within about $10 \mathrm{~min}$. This resulted in the largest mass change, and hence the largest frequency change.

The basic principle of a gas detection tube ${ }^{(11)}$ was applied to the measurement of TCE using a QCM. Oxidizing agents such as lead dioxide $\left(\mathrm{PbO}_{2}\right)$ and sulfuric acid $\left(\mathrm{H}_{2} \mathrm{SO}_{4}\right)$ in 
a gas detecting tube convert TCE to $\mathrm{HCl}$, since the detecting agent in the tube itself does not react with TCE. The detecting agent reacts with the $\mathrm{HCl}$ and the color is changed to reddish purple.

Therefore, we devised a technique for reacting $\mathrm{HCl}$ directly with the surface of the metal electrode of a quartz oscillator. ${ }^{(4)}$ This technique has the following advantages: 1) simplicity, 2) higher sensitivity through the use of a QCM, 3) low cost, and 4) lower sensitivity to the effects of humidity than techniques using a lipid membrane.

In this study, experiments were conducted to examine changes in the temperature, gas flow rate, the installation distance between the QCM and the oxidizing agent, and the quantity of oxidizing agent to clarify the detection characteristics of the monitoring system.

\section{Materials and Methods}

Figure 1 shows the configuration of the experimental equipment in this study.(4) In each experimental run, a new copper electrode for the quartz oscillator and a new oxidizing agent were used. The experimental configuration did not allow the collection of data when the sample gas, quartz oscillator and oxidizing agent were at different temperatures. The copper-modified quartz oscillator used in these experiments is not commercially available. The copper electrodes were fabricated using an electroplating method that allows easy coating. In this study, copper was deposited on a gold electrode element (AT-cut, 9 and $12 \mathrm{MHz}$ ) using a commercially available copper electroplating solution (Marui Galvanizing Co., Ltd, Japan) in our laboratory. The electroplating

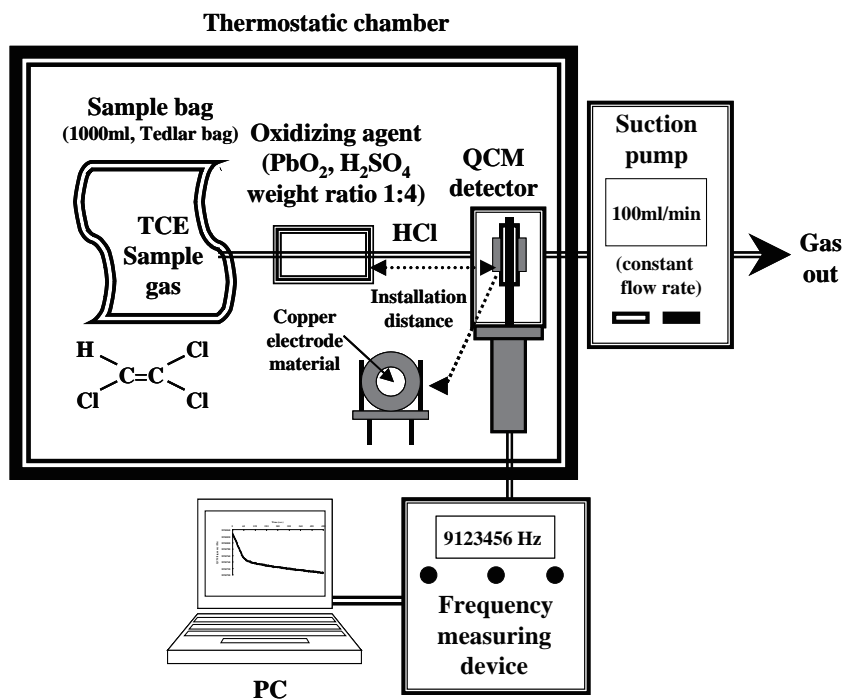

Fig. 1. Schematic diagram of the experimental setup. 
procedure is described as follows: 1) Part of the electrode plate of the oscillator was immersed in a beaker filled with the electroplating solution. 2) The negative side of a constant-current power supply was connected to the terminal of the electrode on the side of the quartz oscillator to be electroplated. In this case, the electrode of the oscillator was used without any pretreatment. 3) The power supply was connected to a platinum wire $(0.5 \mathrm{~mm}$ thick) and the quartz oscillator in the solution. The distance between the oscillator and the platinum wire was about $10 \mathrm{~mm}$. 4) A constant current of $0.5 \mathrm{~mA}$ was applied for 3 min using the power supply. 5) The element was removed from the solution, lightly washed with pure water, and dried at $70^{\circ} \mathrm{C}$ for about $5 \mathrm{~min}$ in an electric drying oven before being used. This process was repeated for each experimental run. This electroplating method resulted in about $16 \mu \mathrm{g}$ (a thickness of about $100 \mathrm{~nm}$ ) of copper being deposited on the electrode with a variation of about $\pm 1 \mu \mathrm{g}$, which accounts for about $7 \%$ of the total amount of copper deposited.

The oxidizing agent used in this experiment was composed of lead oxide and sulfuric acid (weight ratio of about 1:4) supported on silica gel, which is a similar composition to oxidizing agents used in commercially available TCE gas detection tubes.

To keep the temperature constant during each experimental run, pieces of the experimental equipment, such as the sample bag, oxidizing agent, and quartz oscillator (except for the suction pump) were installed in a thermostatic chamber (SH-220, Tabai Espec Co., Ltd.) as shown in Fig. 1. The temperature was set to a given value and controlled within $\pm 0.2^{\circ} \mathrm{C}$.

The standard TCE gas was supplied from a sample bag at a rate of $100 \mathrm{ml} / \mathrm{min}$ for 8 min. To prepare TCE gases with desired concentrations, high-purity nitrogen gas (above 99.99995\%) and the standard TCE gas were mixed at specific ratios. Either $100 \mathrm{ppb}$ or 8.6 ppm TCE gas (nitrogen balance; stored in a steel cylinder) was used as the standard TCE gas. Each of the prepared TCE gases was injected into a Tedlar bag with a capacity of $1000 \mathrm{ml}$. This gas preparation method is similar to that used to derive a calibration curve for a gas detection tube. Because very low concentrations of TCE were measured in these experiments, the Tedlar bag was changed when the TCE concentration was changed. It is known that the TCE sample gases were adsorbed on the inner surfaces of the Tedlar bags. However, it was assumed that this adsorption had almost no effect on the measured values because Tedlar bags of the same type were used.

As described above, TCE gas is converted by the oxidizing agent into $\mathrm{HCl}$ gas. The experimental configuration allows this $\mathrm{HCl}$ gas to diffuse to the surface of the electrode on the quartz oscillator.

Changes in the oscillating frequency output induced by the sample gases (fundamental oscillating frequencies of 9 and $12 \mathrm{MHz}$ ) and the response speed properties were recorded using a personal computer (PC).

\section{Results and Discussion}

Figure 2 shows the change in the measured frequency shift of the QCM as a function of temperature. The experiments in this study are based on the assumption that the device will be used for on-site measurements without any other special instruments. 


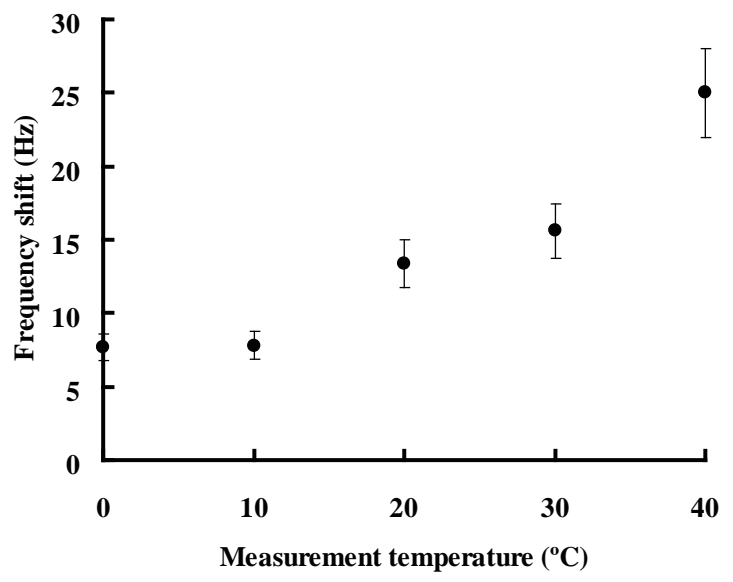

Fig. 2. Frequency shift vs measurement temperature. QCM: AT-cut type, fundamental frequency $9 \mathrm{MHz}$ with a copper element, installation distance $25 \mathrm{~mm}$. The experiments were conducted under the following conditions: $0.1 \mathrm{~g}$ of oxidizing agent $\left(\mathrm{PbO}_{2}, \mathrm{H}_{2} \mathrm{SO}_{4}\right)$, standard TCE gas $100 \mathrm{ppb}$; gas supply flow rate $100 \mathrm{ml} / \mathrm{min}$. The frequency change was observed $8 \mathrm{~min}$ after switching to the sample gas.

Therefore, the measurement temperature was set within the range of $0-40^{\circ} \mathrm{C}$ and centered at the ambient temperature range. Although the frequency shift in the temperature range of $0-10^{\circ} \mathrm{C}$ does not increase, a positive linear relationship between the measurement temperature and frequency shift is observed in the temperature range of $10-40^{\circ} \mathrm{C}$, and the maximum frequency shift reaches about $25 \mathrm{~Hz}$ at $40^{\circ} \mathrm{C}$. A similar tendency was observed at other TCE concentrations. This increase in the frequency shift with increasing temperature implies that higher sensitivity is possible at higher temperatures. The strong dependence of the frequency shift on the measurement temperature $\left(10-40^{\circ} \mathrm{C}\right)$ implies that a sensitivity correction is required. In this case, the chemical reaction of the oxidizing agents depends on the temperature. Therefore, TCE is more actively converted into $\mathrm{HCl}$ as the temperature increases. In addition, it is suggested that the chemical reaction between the copper electrode and $\mathrm{HCl}$ also depends on the temperature. A simplified correction table prepared in advance can be used for temperature correction, if required, for on-site measurement to deal with differences in temperature, as in the case of the gas detection tube.(11) Another possible technique for reducing the effects of temperature differences is to install the measuring instruments in a simple protective box made of an inexpensive, readily available thermal insulator such as styrene foam.

The following method can be used as an alternative to reduce the temperature effect. The QCM sensors can be arranged in a differential structure with one sensor without copper as a reference and another with copper as the sensor. The difference in the signals between the two devices indicates the TCE concentration. 
Figure 3 shows the change in the measured frequency shift of the QCM as a function of the amount of oxidizing agent present. The experimental results indicate that, for a TCE concentration of $1 \mathrm{ppm}$ or less, $0.1 \mathrm{~g}$ or less of the oxidizing agent produced a larger frequency shift, and hence a more favorable result, than $0.4 \mathrm{~g}$ of the oxidizing agent. The frequency shift for $0.05 \mathrm{~g}$ was similar to that for $0.1 \mathrm{~g}$, indicating no significant difference between these two values at any of the observed concentrations. However, the frequency shift for $0.4 \mathrm{~g}$ was less than half that for 0.05 and $0.1 \mathrm{~g}$ at $0.5 \mathrm{ppm}$, while the maximum frequency shift observed for $0.4 \mathrm{~g}$ was about twice the frequency shifts for 0.05 and $0.1 \mathrm{~g}$ at $5.0 \mathrm{ppm}$. These results indicate that larger amounts of oxidizing agent do not necessarily lead to larger frequency shifts, and that the frequency shift depends on the concentration of TCE gas.

Figure 4 shows a photograph of the oxidizing agent as it was filled in the glass tube. The oxidizing agent used in this study was placed in individual glass tubes under the same conditions as those recommended by the manufacturer. For this reason, the fluctuations in the conditions and volume of the agent are considered to be small. Since the oxidizing agent is filled into the same glass tubes, the length of the portion occupied by the oxidizing agent in each glass tube could be easily compared. The length of the portion occupied by the oxidizing agent was about $6 \mathrm{~mm}$ for $0.05 \mathrm{~g}$, about $12 \mathrm{~mm}$ for $0.1 \mathrm{~g}$, and about $48 \mathrm{~mm}$ for $0.4 \mathrm{~g}$, indicating that the length of the portion occupied by $0.4 \mathrm{~g}$ of oxidizing agent was about 8 times that occupied by $0.05 \mathrm{~g}$ of oxidizing agent. In this experiment, TCE gas passing through the glass tube reacts with the oxidizing agent

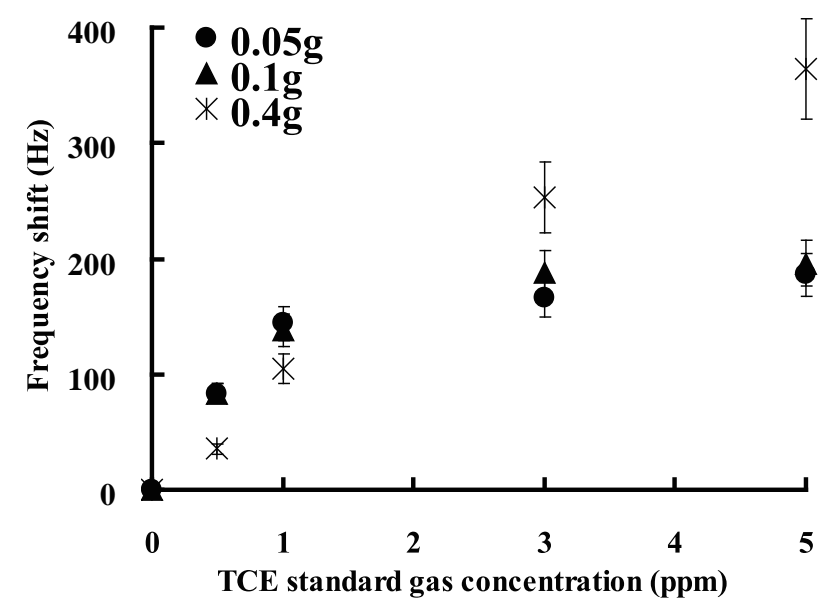

Fig. 3. Frequency shift vs TCE standard gas concentration using different amounts of oxidizing agent. QCM: AT-cut type, fundamental frequency $9 \mathrm{MHz}$ with a copper element, installation distance $25 \mathrm{~mm}$. The experiments were conducted under the following conditions: 0.05, 0.1, and $0.4 \mathrm{~g}$ of oxidizing agent $\left(\mathrm{PbO}_{2}, \mathrm{H}_{2} \mathrm{SO}_{4}\right)$; temperature $30^{\circ} \mathrm{C}$; standard TCE gas $0.5,1$, 3 , and 5 ppm; gas supply flow rate $100 \mathrm{ml} / \mathrm{min}$. The frequency change was observed $8 \mathrm{~min}$ after switching to the sample gas. 


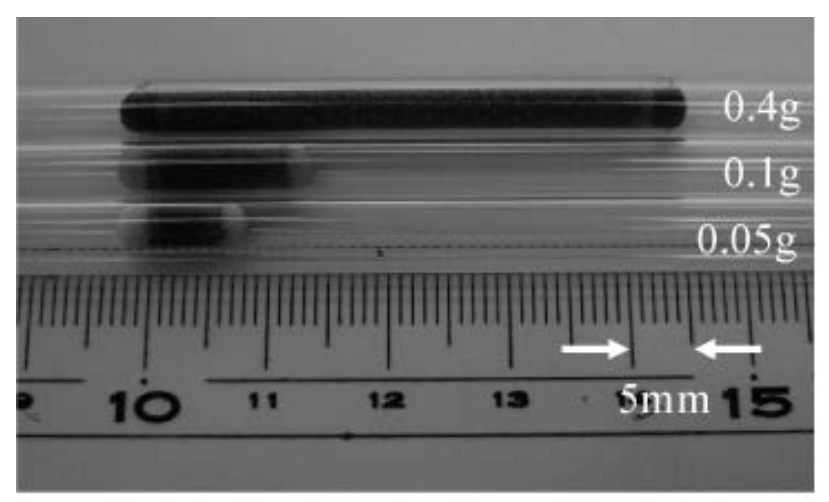

Fig. 4. Photograph of the oxidizing agent $\left(\mathrm{PbO}_{2}, \mathrm{H}_{2} \mathrm{SO}_{4}\right)$.

to generate $\mathrm{HCl}$, which then reacts with the electrode of the oscillator. Since $0.4 \mathrm{~g}$ of oxidizing agent occupies more space than $0.05 \mathrm{~g}$ of oxidizing agent, more $\mathrm{HCl}$ molecules would be adsorbed by $0.4 \mathrm{~g}$ of oxidizing agent simply on the basis of area. In the case of a low concentration of TCE gas, a small amount of $\mathrm{HCl}$ is generated. When a large amount $(0.4 \mathrm{~g})$ of the oxidizing agent is used, the $\mathrm{HCl}$ generated would be adsorbed in the oxidizing agent, and the remaining $\mathrm{HCl}$ would react with the copper electrode, causing a small frequency shift. In contrast, in the case of a high concentration of TCE gas, a large amount of $\mathrm{HCl}$ is generated. Even if a large amount of oxidizing agent is used, adsorbing a small proportion of the $\mathrm{HCl}$ generated, the remaining $\mathrm{HCl}$ reacts with the copper electrode, causing a large frequency shift. As shown in Fig. 3, when 0.05 and $0.1 \mathrm{~g}$ of the oxidizing agent were used, the frequency shifts at 1 and $5 \mathrm{ppm}$ were almost the same. In contrast, when $0.4 \mathrm{~g}$ of the oxidizing agent was used, the frequency shift at $5 \mathrm{ppm}$ was more than three times that at $1 \mathrm{ppm}$. These results indicate that the reactions are saturated above about $1 \mathrm{ppm}$ when 0.05 or $1.0 \mathrm{~g}$ of the oxidizing agent is used. On this basis, 0.05 or $0.1 \mathrm{~g}$ of the oxidizing agent is suitable for measuring TCE gas with a concentration below $1 \mathrm{ppm}$. These results suggest that the optimum amount of oxidizing agent required depends on the concentration of TCE gas in the experiment.

Figure 5 shows the relationship between the frequency shift of the QCM and the flow rate of the gas in the experiment. As shown in Fig. 5, differences in the flow rate caused no significant change in the frequency shift within the measurement range in this experiment. Thus, the relative difference between the frequency shift values is much smaller than that between the flow rate values. Therefore, within the flow rate range in this experiment, a difference in the flow rate does not have a significant effect on the results.

The effect of the installation distance between the quartz oscillator and the oxidizing agent on the TCE detection properties was investigated. In this experiment, measurements were taken over oscillator-to-agent distances between 25 and $50 \mathrm{~mm}$ at intervals of $5 \mathrm{~mm}$. Figure 6 shows the results. As shown in the Fig. 6, no significant 


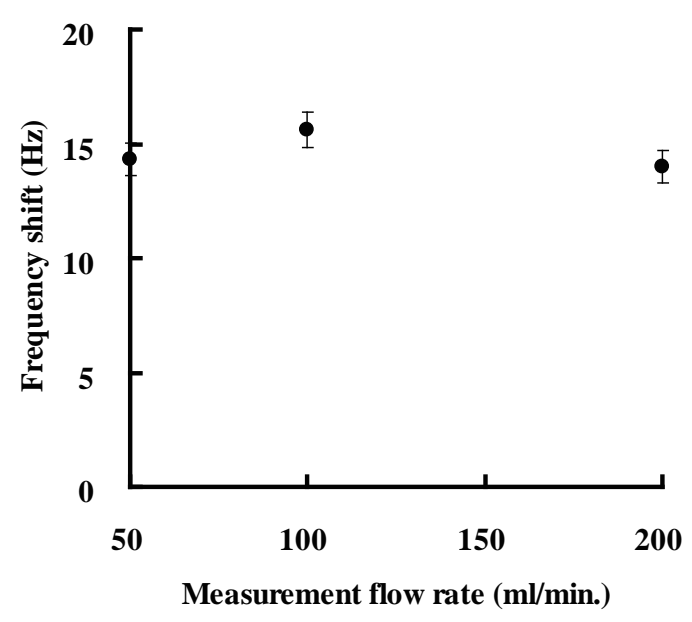

Fig. 5. Frequency shift vs measurement flow rate. QCM: AT-cut type, fundamental frequency $9 \mathrm{MHz}$ with a copper element, installation distance $25 \mathrm{~mm}$. The experiments were conducted under the following conditions: $0.1 \mathrm{~g}$ of oxidizing agent $\left(\mathrm{PbO}_{2}, \mathrm{H}_{2} \mathrm{SO}_{4}\right)$; temperature $30^{\circ} \mathrm{C}$; standard TCE gas $100 \mathrm{ppb}$. The frequency change was observed after $800 \mathrm{ml}$ of the sample gas was used.

change in the frequency shift was observed upon changing the oscillator-to-agent distance. In particular, although the oscillator-to-agent distance was doubled from 25 to $50 \mathrm{~mm}$, the frequency shift decreased by only about $10 \%$. These results indicate that, within the measured range in this experiment, a small difference in the oscillator-to-agent distance does not have a significant effect on the results, which indicates that the device will be easy to handle in on-site measurements.

Figure 7 shows the relationship between the TCE gas concentration and the change in frequency over a concentration range of 0 to $1000 \mathrm{ppb}$ TCE. This figure reveals that the frequency shift changes linearly in the TCE concentration range of 0-1000 ppb, which indicates that there is a positive correlation between the standard TCE gas concentration and the frequency shift.

Using this correlation, the following approximate equation was derived:

$$
Y_{\mathrm{ppm}(9 \mathrm{MHz})}=6.7 \cdot X_{\mathrm{qcm}}
$$

where $Y_{\mathrm{ppm}(9 \mathrm{MHz})}$ is converted TCE concentration (ppb) (a time of 8 min corresponds to $800 \mathrm{ml}$ of suction gas) and $X_{\mathrm{qcm}}$ is frequency shift (Hz).

These results indicate that, in experiments that use the combination of an oxidizing agent and a QCM to measure TCE concentration, the frequency shift can be converted to a TCE concentration using this approximate equation within the range where the frequency shift is proportional to the TCE concentration. The relationship of the 


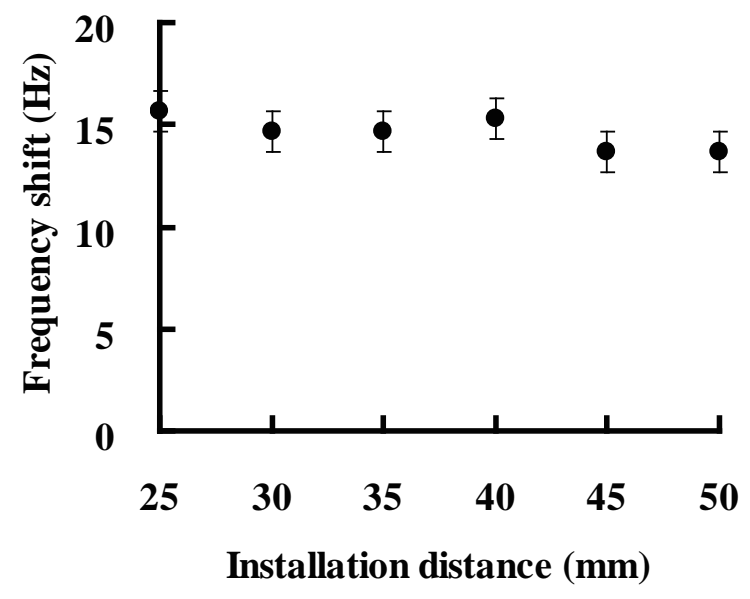

Fig. 6. Frequency shift vs QCM installation distance. QCM: AT-cut type, fundamental frequency $9 \mathrm{MHz}$ with a copper element. The experiments were conducted under the following conditions: $0.1 \mathrm{~g}$ of oxidizing agent $\left(\mathrm{PbO}_{2}, \mathrm{H}_{2} \mathrm{SO}_{4}\right)$; temperature $30^{\circ} \mathrm{C}$; standard TCE gas $100 \mathrm{ppb}$; gas supply flow rate $100 \mathrm{ml} / \mathrm{min}$. The frequency change was observed $8 \mathrm{~min}$. after switching to the sample gas.

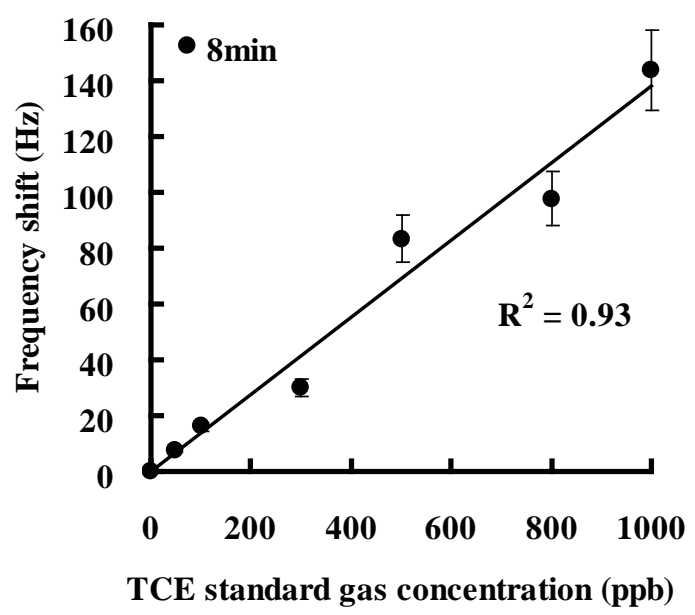

Fig. 7. Frequency shift vs standard TCE gas concentration (0-1000 ppb). QCM: AT-cut type, fundamental frequency $9 \mathrm{MHz}$ with a copper element, installation distance $25 \mathrm{~mm}$. The experiments were conducted under the following conditions: $0.05 \mathrm{~g}$ of oxidizing agent $\left(\mathrm{PbO}_{2}\right.$, $\mathrm{H}_{2} \mathrm{SO}_{4}$ ); temperature $30^{\circ} \mathrm{C}$; gas supply flow rate $100 \mathrm{ml} / \mathrm{min}$. The frequency change was observed $8 \mathrm{~min}$ after switching to the sample gas. 
reactions between the oxidizing agents and TCE is important in this hybrid QCM measurement, and specifically the approximation equation derived from the experiments is mainly affected by the temperature. As described previously, chemical reaction of the oxidizing agents is more activated and then TCE is converted to $\mathrm{HCl}$ under the temperature increase. As a result, the chemical reaction with the copper electrode also become active, and the detection sensitivity is higher. In this case, the factor in the equation increases.

On the basis of these results, a conversion table prepared in advance could be used to determine TCE concentrations easily in on-site measurements, as in the case of using gas detection tubes. In addition, all the results indicate that, even if the generation of $\mathrm{HCl}$ reaches a saturation point due to a shortage of oxidizing agent, frequency shift values recorded during measurement can still be converted to TCE concentration values in onsite measurements of TCE gas with unknown concentrations. In this case, conversion tables for smaller amounts of TCE sample gas need to be prepared in advance.

As shown in Fig. 7, a frequency shift of about $16 \mathrm{~Hz}$ was observed at a TCE concentration of $100 \mathrm{ppb}$ at $30^{\circ} \mathrm{C}$. To obtain the optimal frequency shift value ${ }^{(4)}$ based on all results, $100 \mathrm{ppb}$ of TCE sample gas was measured at a suction rate of $100 \mathrm{ml} / \mathrm{min}$ at $30^{\circ} \mathrm{C} 8 \mathrm{~min}$ after the start of the gas supply (amount of standard TCE gas: $800 \mathrm{ml}$ ) using a copper-coated $(16 \mu \mathrm{g})$ gold electrode element on an oscillator (AT-cut, $12 \mathrm{MHz}$ ) and 0.05 g of oxidizing agent. As a result, a frequency shift of $27 \mathrm{~Hz}$ was obtained at $100 \mathrm{ppb}$. This experimental result shows that the detection sensitivity is improved by a factor of 1.7 compared with that shown in Fig. 7.

The results in this study indicate that this method can be used to measure of TCE with a concentration of $0.2 \mathrm{mg} / \mathrm{m}^{3}$, which represents the Japanese guideline value for atmospheric concentration of TCE, corresponding to about $37 \mathrm{ppb}$ at $25^{\circ} \mathrm{C}$. This concentration of TCE cannot be detected using a conventional gas detection tube.

The effects of other gases were investigated using the same experimental configuration. The results indicate that normal air (oxygen, nitrogen, carbon dioxide) caused no frequency shift. Aromatic compounds (such as benzene and toluene) and ethanol with concentrations of several ppm or less also caused no frequency shift. Considering that it would be very unusual for a normal atmosphere to contain gas components that rapidly react with copper on the time scale of these measurements (several min), measurements under such normal conditions should not be affected by other gases. However, because the basic principle of gas detection tubes was applied to TCE detection in this study, unsaturated volatile chloroorganic compounds such as perchloroethylene (PCE), which reacts with the oxidizing agent used to generate $\mathrm{HCl}$, would induce a similar or greater frequency shift. An environmental standard not only for TCE but also for PCE has already been set in Japan. It is possible that this measurement technique could also be effectively used for PCE measurement, although it cannot separately detect TCE and PCE. Moreover, since it is known that ethylene at a concentration of several thousand ppm affects measurements based on gas detection tubes, ${ }^{(11)}$ ethylene would have a similar effect on the QCM-based measurement method in this study. However, in general, the effect of ethylene would not need to be considered in on-site measurements of the air and soil, which are unlikely to contain such a high concentration of ethylene except in special cases. 


\section{Acknowledgements}

This reseach was funded by the Steel Industry Foundation for the Advancement of Environmental Protection Technology. The authors also acknowledge Minoru Tanigawa (AIST) for his technical assistance and Kunitoshi Matsunobu of Gastec Corporation.

\section{References}

1 Japan Environmental Management Association for Industry: Environmental Handbook (Maruzen Co., Ltd., Tokyo, 2002).

2 Ministry of the Environment: Quality of the Environment in Japan 2003 (White Paper) (Gyosei Corp., Tokyo, 2003).

3 K. Noda, R. Naganawa, H. Tao, M. Tominaga, A. Miyazaki and N. Kamimura: Trans. IEE Jpn. 118-E (1998) 590.

4 K. Noda, R. Naganawa, Y. Kanekiyo and H. Tao: Chem. Lett. 32 (2003) 1128.

5 G. Z. Sauerbrey: Z. Phys. 155 (1959) 206.

6 Y. Okahata, G. En-na and H. Ebato: Anal. Chem. 62 (1990) 1431.

7 T. Matsumoto, K. Tanabe, S. Kurosawa, T. Mukai and H. Nanto: Chem. Software 22 (2000) 85.

8 H. Nanto, Y. Hamaguchi, Y. Yokoi, S. Kurosawa, T. Oyabu, E. Kusano and A. Kinbara: Sen. Mater. 13 (2001) 69.

9 S. Kurosawa, N. Kamo, D. Matsui and Y. Kobatake: Anal. Chem. 62 (1990) 353.

10 H. Aizawa, S. Kurosawa, M. Tozuka, J. W. Park, K. Kobayashi and H. Tanaka: Biosens. Bioelectron. 18 (2003) 765.

11 Gastec Corporation: Environmental Analysis Technology Handbook, 3rd Ed. (Gastec Corporation, Kanagawa, 2002). 